\section{Covid-19 booster vaccines: What we know and who's doing what}

\author{
The virulence of the delta variant has prompted many countries to start administering booster \\ vaccines. Elisabeth Mahase looks at what is happening where
}

\author{
Elisabeth Mahase
}

\section{Do we need booster doses?}

How long does immunity after covid-19 vaccination last? It's something everyone would like to know, but it's a question that can't currently be answered with certainty. ${ }^{1}$

There is some evidence that immunity does wane, especially against the delta variant. Researchers have found that a single dose of either the

Oxford-AstraZeneca or Pfizer-BioNTech vaccine is only around 30\% effective against delta, although two doses are more effective: $88 \%$ for Pfizer and $67 \%$ for AstraZeneca. ${ }^{2}$

A preprint from Israeli researchers has reported that the risk of infection is significantly higher among people who were vaccinated earlier in the pandemic than among those vaccinated later (with the Pfizer vaccine only), suggesting a "possible relative decrease in the long-term protection of the BNT162b2 [Pfizer] vaccine against the delta variant of SARS-CoV-2." ${ }^{3}$ The Israeli team did not look at the effect of time of vaccination on the incidence of symptomatic infection, severe disease, or hospital admissions.

But there is a view that booster doses should not be prioritised over primary vaccination. In June researchers from the University of Oxford vaccine team that developed the AstraZeneca vaccine said that although a third dose of their vaccine can provide a strong boost to the immune response there was no indication that a booster was needed and emphasised that the "urgent priority" should be to ensure that people around the world got their first dose. ${ }^{4}$

Despite nearly 35 million doses of covid-19 vaccines being administered every day, only $1.3 \%$ of people in low income countries have received at least one dose. Just under a third (32\%) of the world's population has had at least one dose, and only a quarter (24\%) have had two. ${ }^{5}$

The World Health Organization has called for a moratorium on boosters until at least the end of September, to enable a minimum of $10 \%$ of the population of every country to be vaccinated. WHO's director general, Tedros Adhanom Ghebreyesus, said in a speech on 4 August, "I understand the concern of all governments to protect their people from the delta variant. But we cannot accept countries that have already used most of the global supply of vaccines using even more of it, while the world's most vulnerable people remain unprotected." 6

\section{Which countries are planning booster shots?}

Many high and middle income countries have been discussing booster doses (a third dose, in most cases) as a way to ensure that people remain protected against new variants of SARS-CoV-2 as the winter months approach.

By 18 August more than nine million booster doses had been administered worldwide. ${ }^{7}$

In Israel more than one million people have received a third dose of the Pfizer vaccine after the government started its booster campaign aimed at over $50 .^{8}$

Turkey started administering booster doses in July to healthcare workers and people over 50. The country, which uses the Sinovac and Pfizer vaccines, is now also allowing people who had the Sinovac vaccine to have the Pfizer vaccine too so they can travel to countries that do not recognise the Chinese vaccine. ${ }^{9}$

A similar initiative is being rolled out in Uruguay, where citizens who received the Sinovac vaccine are being offered a dose of the Pfizer vaccine to boost their immune response. ${ }^{10}$ And in Cambodia and Thailand the AstraZeneca vaccine is being offered as a booster to people who received either the Sinovac or Sinopharm vaccine. ${ }^{11}$

The US is expected to roll out booster shots to most adults from 20 September, with the third dose recommended to be given eight months after the second. Healthcare workers, nursing home residents, and older adults who got the vaccines early on will be prioritised for the booster. ${ }^{12}$

However, so far the US Food and Drug Administration has amended the emergency use authorisations only for the Pfizer and Moderna covid-19 vaccines, to allow for a third booster dose to be given to certain immunocompromised people, including organ transplant recipients and those who have diagnosed conditions that are considered to have an equivalent level of immunocompromise. The FDA is carrying out a safety and efficacy review of the booster dose in other members of the adult population, while the Centers for Disease Control and Prevention is conducting a review of the evidence.

In the UK the health system has been preparing for a booster dose to be rolled out in September to patients considered at risk of serious illness. However, the Times newspaper has reported that the UK Joint Committee on Vaccination and Immunisation is waiting for more data before making a final decision on whether to recommend a booster programme. ${ }^{13}$

France and Germany are also planning to roll out third vaccine doses in September to elderly and vulnerable people, including immunocompromised people and care home residents. Ecuador is planning 
to roll out booster doses of the Pfizer, AstraZeneca, and Sinovac vaccines to people with weakened immune systems. Its health ministry has said it will carry out research to determine whether the wider population should also receive a third dose. ${ }^{14}$

\section{Will people get the same vaccine brand for their booster?}

This varies. Uruguay, Cambodia, and Thailand are mixing vaccines, while the US has decided not to mix brands. People who received two doses of the Pfizer or Moderna vaccines in the US will be given a third dose of the same vaccine. However, people who received the one dose Johnson \& Johnson vaccine will not be offered a second dose as yet, as officials are waiting on efficacy results from the drug company. ${ }^{15}$

In Ireland, vaccine brands are to be mixed, with people who had a single dose of the AstraZeneca vaccine but did not opt to have a second dose currently being offered a dose of the Pfizer or Moderna vaccine. It's likely that vaccine mixing will be allowed when booster doses are rolled out in October. ${ }^{16}$

\section{Might we need annual covid vaccinations?}

This is certainly a possibility, said Anthony Harnden, a member of the Joint Committee on Vaccination and Immunisation. Speaking on The BMJ's Talk Evidence podcast in March, he said, "I suspect it's going to be likely that we're going to require an annual boost for a while... It just depends on the length of duration of protection. The virus mutates, [but it] probably doesn't mutate as much or as quickly as the influenza virus, so it's very difficult to predict whether this is going to be an annual vaccine or for how many years." 17

1 Baraniuk C. How long does covid-19 immunity last?BM/2021;373:n1605. doi: 10.1136/bmj.n1605. https://www.bmj.com/content/373/bmj.n1605. pmid: 34193457

2 Mahase E. Covid-19: Two vaccine doses are crucial for protection against delta, study finds. BMJ 2021;374:n2029. doi: 10.1136/bmj.n2029. https://www.bmj.com/content/374/bmj.n2029. pmid: 34400411

3 Mizrahi B, Lotan R, Kalkstein N, et al. Correlation of SARS-CoV-2 breakthrough infections to time-from-vaccine: preliminary study. medRxiv 2021: 21261317v1 [preprint]. https://www.medrxiv.org/content/10.1101/2021.07.29.21261317v1.full.pdf.

$4 \quad$ Mahase E. Covid-19: Third vaccine dose boosts immune response but may not be needed, say researchers. BMJ 2021;373:n1659. doi: 10.1136/bmj.n1659. https://www.bmj.com/content/373/bmj.n1659. pmid: 34187780

5 Coronavirus (COVID-19) vaccinations. Our World in Data. https://ourworldindata.org/covid-vaccinations

6 WHO Director-General's opening remarks at the media briefing on COVID-19-4 August 2021. https://www.who.int/director-general/speeches/detail/who-director-general-s-opening-remarksat-the-media-briefing-on-covid-4-august-2021

7 COVID-19 vaccine booster doses administered. Our World in Data. 2021. https://ourworldindata.org/explorers/coronavirus-data-explorer?zoomToSelection=true\&facet=none\&pickerSort=asc\&pickerMetric=location\&Metric=Vaccine+booster+doses\&Interval=7-day+rolling+average\&Relative+to+Population=false\&Align+outbreaks=false\&country= OWID_WRL

8 A million Israelis get third dose, with early data showing heightened protection. Times of Israel. 2021. https://www.timesofisrael.com/a-million-israelis-get-third-dose-with-early-data-showingheightened-protection/

9 Turkey offering extra Pfizer shots for those wanting to travel. Reuters. 2021 https://www.reuters.com/world/middle-east/turkey-offering-extra-pfizer-shots-those-wantingtravel-2021-08-16/

10 Today, Uruguayans vaccinated with Coronavac can receive a Pfizer booster dose. Rio Times. 2021. https://riotimesonline.com/brazil-news/covid-19/starting-today-those-vaccinated-withcoronavac-in-uruguay-will-receive-a-booster-dose-from-pfizer/

11 Cambodia starts vaccine booster drive to shore up COVID-19 defence. Reuters. 2021 https://www.reuters.com/world/asia-pacific/cambodia-starts-vaccine-booster-drive-shore-upcovid-19-defence-2021-08-12/

12 Joint statement from HHS public health and medical experts on COVID-19 booster shots. Department for Health and Human Services. https://www.hhs.gov/about/news/2021/08/18/jointstatement-hhs-public-health-and-medical-experts-covid-19-booster-shots.html

$13 \mathrm{https}: / /$ www.thetimes.co.uk/article/experts-will-delay-covid-vaccine-boosters-decision-nj8fpvdxp

14 Ecuador to give immune-weakened people third COVID-19 vaccine. Reuters. 2021.

https://www.reuters.com/world/americas/ecuador-give-immune-weakened-people-third-covid19-vaccine-2021-08-17/
15 COVID-19 vaccines for moderately to severely immunocompromised people. Centers for Disease Control and Prevention. 2021. https://www.cdc.gov/coronavirus/2019-ncov/vaccines/recommendations/immuno.html

16 Green light for mixing of Covid-19 vaccines paves way for winter booster campaign. Independent. 2021. https://www.independent.ie/world-news/coronavirus/green-light-for-mixing-of-covid-19vaccines-paves-way-for-winter-booster-campaign-40761003.html

17 Mahase E. Covid-19: Booster dose will be needed in autumn to avoid winter surge, says government adviser. BMJ2021;372:n664. doi: 10.1136/bmj.n664. https://www.bmj.com/content/372/bmj.n664. pmid: 33687925

This article is made freely available for use in accordance with BMJ's website terms and conditions for the duration of the covid-19 pandemic or until otherwise determined by BMJ. You may use, download and print the article for any lawful, non-commercial purpose (including text and data mining) provided that all copyright notices and trade marks are retained. 